\title{
Numerical Simulation on the Mean Wind Pressure Distribution on Roofs of Low-rise Gable-Roofed Buildings
}

\author{
WANG Yin-kun ${ }^{1, a}$, HUO Lin-sheng ${ }^{1, b}$ and LI Gang ${ }^{1, c}$ \\ 1. State Key Lab of Coastal and Offshore Engineering, Dalian University of Technology, Dalian,
China \\ awangyinkun1222@163.com, ${ }^{b}$ Ishuo@dlut.edu.cn, gli@dlut.edu.cn
}

Keywords: Low-rise gable roofed buildings; Numerical simulation; Roof pitch; Division of the roof; Mean wind pressure

Abstract: In this paper, numerical simulation method was applied to study the wind-induced pressure distribution on the roofs of low-rise gable roofed buildings. First, the numerical simulation was performed based on Fluent 14.5 software platform, and the results were compared with wind tunnel test results to validate the accuracy and feasibility of numerical simulation. Then the mean wind pressure distribution characteristics and variation laws of the partial roofs of low-rise gable roofed buildings with different roof pitches were analyzed. Finally, the wind pressure distribution characteristics of low-rise gable roofed buildings surface were analyzed and summarized. The wind pressure distribution has obvious positive and negative pressure areas. The windward sides are mainly affected by positive pressure, and the negative pressure area is very small. On the contrary, the negative pressure effect on leeward sides is obvious. And higher negative wind pressure can appear at some partial areas, such as eaves, ridges and gable top edges, etc.

\section{Introduction}

In recent years, the southeastern coastal areas of China have suffered from typhoons frequently, and the trend of increasing year by year is obvious, causing a great loss of lives and property to the residents of southeast coastal provinces. ${ }^{[1]}$ All the previous researches on typhoon disasters show that the wind resistance ability of these low-rise buildings is poor, in all kinds of houses destroyed by typhoons, low-rise buildings are usually more than half, ${ }^{[2]}$ and the roofs of low-rise gable roofed buildings are more prone to suffer from the wind-induced damage compared with the main structure. Therefore, it is a critical work to strengthen analysis and study on wind pressure characteristics of the roofs and put forward some feasible protective measures at present.

The study of the wind load characteristics of low-rise houses should mainly focus on the rules of mean wind pressure distribution coefficients of the roofs and the laws that the pressure peak values change with time and space. ${ }^{[3]}$ To know the wind load characteristics of roof is the first step to study the wind resistance of buildings' roofs. Only the wind load characteristics of roof structure are fully mastered, can we establish the reasonable analytical methods for wind vibration response. Besides, we can study the wind load distribution characteristics of the roof structure by wind tunnel test, numerical simulation and field measurement and so on. At present, with the rapid development of computer technology and the increasing perfect of fluid dynamics theory, numerical simulation technology has become an effective method to study the wind effects on buildings. ${ }^{[4]}$ In this paper, we mainly used numerical simulation to study the wind load characteristics of buildings' roofs.

\section{Foundation of Numerical Model}

The size of the real house corresponds to numerical simulation model is: $10 \mathrm{~m}$ in length, $6 \mathrm{~m}$ in width and $7 \mathrm{~m}$ in height (cornice height). Considering the optimization of numerical wind tunnel size and the blocking rate requirements, the size of computational domain is $180 \mathrm{~m}$ long, $90 \mathrm{~m}$ wide, and $80 \mathrm{~m}$ high. Considering the researches focus on the wind pressure of buildings' roofs, so the meshing size of roofs should be finer, and the other parts of computational domain can be relatively rougher, thus the 
computational domain is divided into the internal and external drainage basin. Incorporating the existing computational efficiency and computational resources problems, the computational domain grids should adopt the mixed grids in discrete form ${ }^{[5]}$, which adopts the meshing way to combine the simple tetrahedral unit and the relatively complicated hexahedral unit (with the regular topological structure). Thus it controls the total number of grids within a certain range effectively, making it easier to calculate(Fig.1).

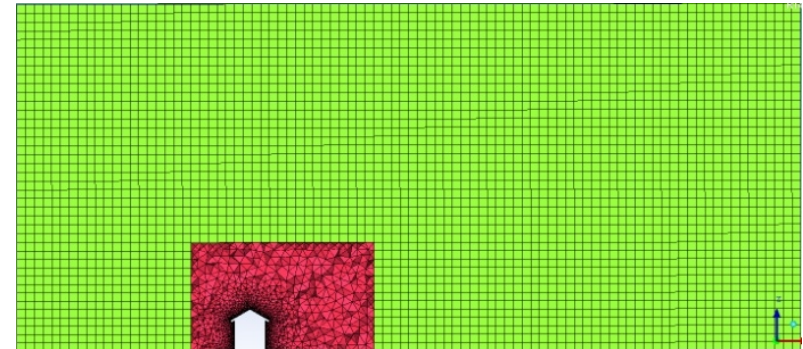

(a)

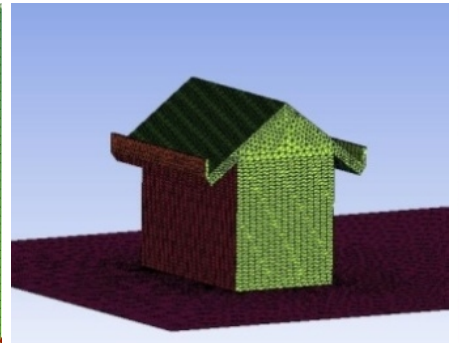

(b)

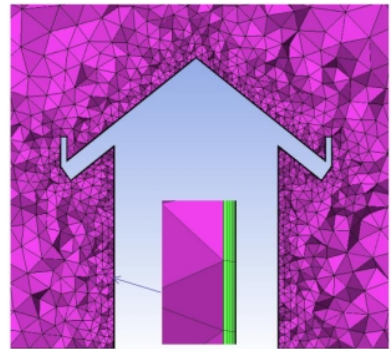

(c)

Fig.1 Computing field grids and boundary grids of house model

\section{Data Processing}

In order to verify the veracity and reliability of the numerical simulation results, the roof was first divided into different block areas. Then the numerical simulation results and the wind tunnel test results of mean wind pressure coefficients $\mathrm{C}_{p}$ of low-rise gable roofed buildings' roof were compared under $0^{\circ}$ and $90^{\circ}$ coming wind directions respectively(Fig.2).
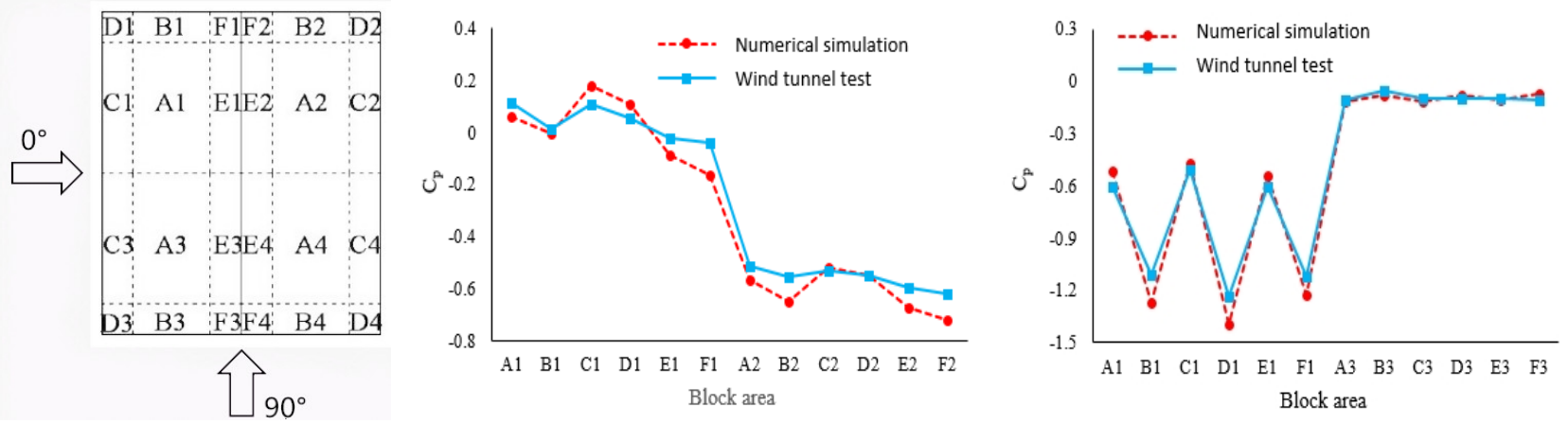

Fig.2 Comparison between the numerical simulation results and wind tunnel test results of $\mathrm{C}_{p}$ of some local roof areas under wind direction of $0^{\circ}$ and $90^{\circ}$

The above comparison results show that: the numerical simulation results coincide well with the wind tunnel test results on the whole, which illustrates that the numerical simulation method is accurate and reliable to simulate mean wind pressure on the roofs of low-rise gable roofed buildings. ${ }^{[7]}$

In order to study the effect of roof pitches on the mean wind pressure distribution of the roofs of low-rise gable roofed buildings, the variations of mean wind pressure coefficients of different roof areas with different roof pitches $\left(15^{\circ}, 25^{\circ}, 30^{\circ}, 35^{\circ}\right.$ and $\left.45^{\circ}\right)$ are simulated using numerical simulation method (as shown in Fig.3 and Fig.4), and the mean wind pressure distribution characteristics and variation rules of partial roof areas are summed up.

It can be seen from Fig. 3, under $0^{\circ}$ wind direction, the rules that the mean wind pressure coefficients of each windward roof area (A1 F1) vary with the roof pitches are basically consistent, namely the mean wind pressure coefficients change from negative to positive along with the increase of roof pitch. At the same time, it can also be found that $30^{\circ}$ is the turning point that the mean wind pressure values of windward roofs vary from negative to positive. When the roof pitch is less than $30^{\circ}$, the windward sides present negative pressure overall, the smaller the roof pitch, the bigger the absolute values of 
negative pressure, subsequently the positive pressure areas and values also increase with the increase of roof pitch. ${ }^{[8]}$

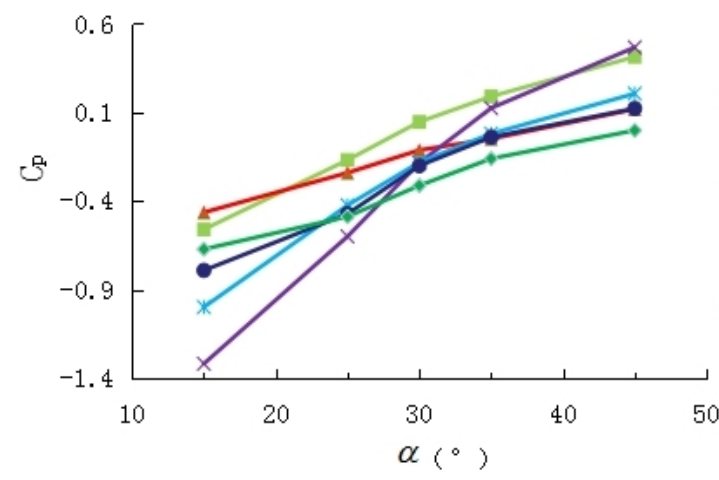

Fig.3 Variation of $\mathrm{Cp}$ of windward roofs with roof pitches under $0^{\circ}$ wind direction

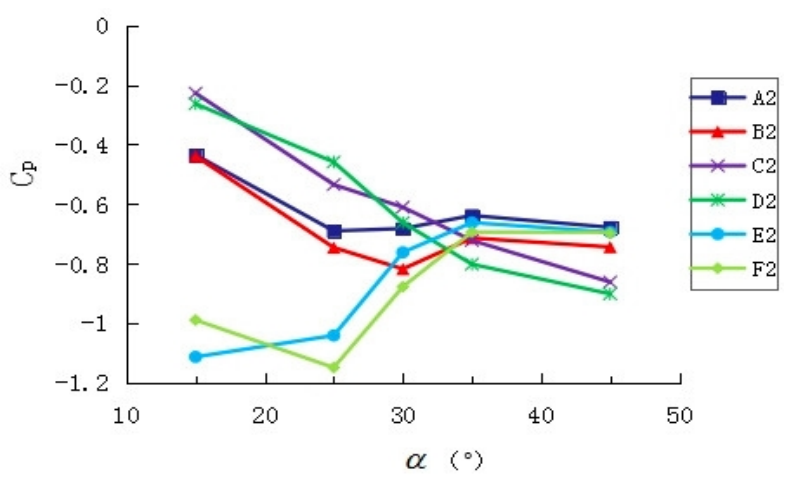

Fig.4 Variation of Cp of leeward roofs with roof pitches under $0^{\circ}$ wind direction

It can be obtained from Fig.4, for the leeward roof, it presents negative pressure overall under each roof pitch. when the roof pitch is less than $25^{\circ}$, the difference of mean wind pressure coefficients between each area is large, while when it is greater than $25^{\circ}$, the mean wind pressure coefficients of each area are well distributed. when the roof pitch is $15^{\circ}$, the maximum negative pressure areas are leeward roof ridge (E2, F2), which decrease with the increasing roof pitch. The negative pressure absolute values of the rest areas are minimum, which increase with the increase of roof pitch in leeward eave areas (C2 and D2).

Fig. 5 shows the numerical simulation contour map of mean wind pressure coefficients of the model surface when the wind is perpendicular to the ridge. Judging from the results, when the wind is perpendicular to the ridge, the wind pressure on model surface roughly presents symmetrical distribution. Windward walls are all affected by positive pressure, the maximum appeared in the middle and upper area. The gables and leeward walls are affected by negative pressure, the maximum negative pressure of gables appears in the flow separation place near the windward walls, and the negative pressure gradient is large, while the negative pressure distribution of leeward walls is relatively uniform. The wind pressure of windward roofs is also evenly distributed, the central area is subjected to relatively low positive pressure, but the eaves and ridges are affected by negative pressure. The Leeward roof is mainly influenced by wind suction, and the negative pressure ranges widely.

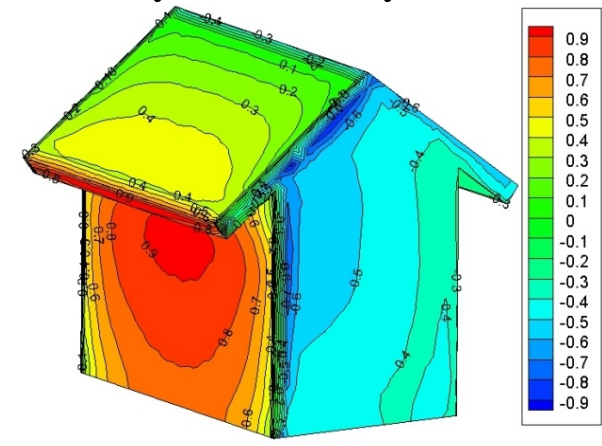

( a )

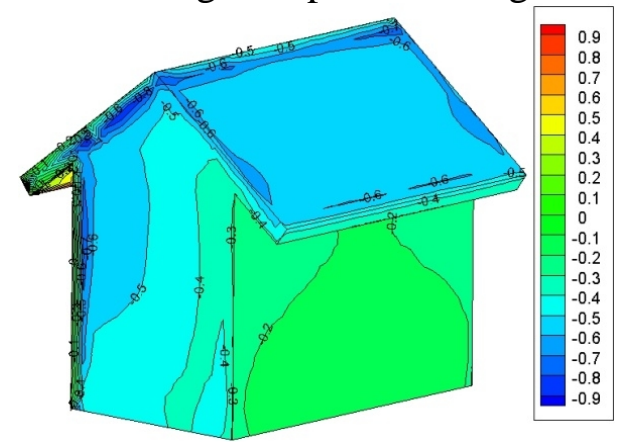

( b )

Fig.5 The mean wind-pressure coefficients of building surface

\section{Conclusions}

The numerical simulation method has been applied to study the wind-induced pressure distribution on the roofs of low-rise gable roofed buildings in this paper. First, the numerical simulation results were compared with wind tunnel test results to validate the correctness and feasibility. Then the roof partial mean wind pressure distribution characteristics and variation laws of the low-rise gable 
roofed buildings with different roof pitches were analyzed. Finally, the wind pressure distribution characteristics of low-rise gable roofed buildings were analyzed and concluded. The main conclusions are as follows:

( 1 )Looking from the overall distribution and trend, the results obtained from the wind tunnel test and the numerical simulation can match well. This results indicated that the wind tunnel test and numerical simulation method can make cross-reference and verification to study the roof wind load characteristics of the low-rise buildings mutually, which provided theoretical and analysis basis for the wind-resistant study on low-rise buildings.

( 2 )The roof pitch has a great influence on the roof wind pressure distribution of low-rise gable roofed buildings. For windward roofs, the rules that the mean wind pressure coefficients of each block area vary with roof pitches are basically consistent. That is, the mean wind pressure coefficients vary from negative to positive along with the increase of roof pitch. However, The variation rules are different for leeward roofs, the absolute value of negative pressure at the leeward roof ridges (E2, F2) decreases with the increase of roof pitch, while it increases at the leeward roof eaves (C2 and D2).

( 3 ) The wind pressure distribution on the roofs of low-rise gable roofed buildings has obvious positive pressure and negative pressure area. The windward sides are mainly affected by positive pressure, and the negative pressure area is small; On the contrary, the negative pressure effect on leeward sides is obvious. And higher negative wind pressure can appear at some local regions, such as eaves, ridges and gable top edges, etc.

\section{Acknowledgment}

This work was supported by the national "12th Five-year" Plan for Science \& Technology Pillar Program (2014BAL05B03). Innovation Group Program of National Natural Sciences Foundation of China (51421064). The Fundamental Research Funds for the Central Universities(DUT16TD03).

\section{References}

[1] X. G. Yan, Y. M. Dai. Study of local wind pressures on windward roof of low-rise buildings [D]. Xiangtan: Hunan University of Science and Technology. 2014.

[2] X. P. Zhou, X. Q. Peng. Influence to wind pressures on the roof of low-rise gable-roofed building with cantilevered parapets [D]. Quanzhou: Huaqiao University. 2008.

[3] G. H. Fu. On the wind load characteristics and wind resistant design of low-rise buildings [D]. Zhejiang University. 2002.

[4] Y. M. Dai, Q. S. Li, Z. N. Li. Field measurements and analysis of pressures on roof of low-rise buildings [J]. Building Structure. 2009, 39 (7): 88-89.

[5] M. Y. Li, G. Li. Numerical simulation of surface wind load and wind resistant design for low-rise buildings in southeast coastal areas [D]. Dalian: Dalian University of Technology. 2015.

[6] Y. X. Li, G. Li. Wind-induced Mean Interference Effects between Low-rise Buildings with Gable Roof [D]. Dalian: Dalian University of Technology. 2016.

[7] M. Gu, Y. L. Zhao, Q. Huang, P. Huang, Y. Quan, Z. N. Xie. Wind tunnel test and numerical simulation of mean wind pressures on roof of low-rise buildings [J]. Acta Aerodynamica Sinica. 2010, 28(1): 82-87.

[8] M. Gu, Q. Huang, P. Huang. Numerical simulation of effects of roof factors on mean wind pressure on gable-roofed low-rise buildings with eaves [J]. Journal of Building Structures. 2009, 30(5):205-211. 